\title{
Presencia de salmonella spp en expendios de carne de pollo de la ciudad de Valledupar
}

\author{
Álvaro Araujo Guerra \\ M.V.Z. M.Sc. Escuela de Ciencias Agrícolas, Pecuarias y del Medio Ambiente, Universidad Nacional Abierta y a \\ Distancia. Grupo de investigación ZooBios. \\ alvaro.araujo@unad.edu.co
}

\section{Introducción}

La producción de alimentos de origen animal es fundamental para la supervivencia de las personas, porque generan la proteína que el cuerpo humano necesita. Hoy en día hay gran concientización alrededor del consumo de la carne de pollo, pues se ha establecido que es una de las más saludables, junto con la de pescado (Alvarado, et al, 2012). Para encarar este hecho, ha surgido una tendencia científica denominada ciencia de la sostenibilidad, la cual se ha considerado que debe ser una ciencia inspirada en el uso del conocimiento y debe tener características como la transdisciplinariedad, la participación, el aprendizaje social, la co-producción de conocimiento, la visualización de múltiples escalas y el manejo de la incertidumbre (Salas \& Ríos, 2013).

La carne de pollo es uno de los alimentos de mayor consumo en el país; esta cuenta con un gustoso sabor y un costo menor a otras carnes. Lastimosamente este alimento es un foco de enfermedades como campilobacteriosis, listeriosis, infecciones por Escherichia coli y salmonelosis (Castañeda et al, 2013). Siendo esta última una de las principales afecciones trasmitidas por la carne de pollo, dividiéndose en salmonelosis tifoidea y no tifoidea. El agente etiológico de la enfermedad es Salmonella spp., bacteria que se encuentra como nativa en los intestinos de animales como pollos y cerdos principalmente (Adams y Moss, 2008).

En países tropicales como Colombia las condiciones ambientales y productivas favorecen la transmisión y replicación de la enfermedad; variables como la precipitación, humedad, temperatura, estructura y composición del suelo (Moreno \& Trujillo, 2015), pero es evidente que los procesos de la trasmisión de la salmonelosis se dan en su mayoría por malas prácticas de manipulación y fallas en la temperatura de almacenamiento. La carne de pollo tiene una vida útil menor a la de otras carnes, influenciada por la temperatura, variando de 4 días a $9 \mathrm{C}^{\circ}$ y 9 días a $7 \mathrm{C}^{\circ}$ días. En el país existen expendios informales de carne de pollo crudo como las tiendas de barrio y mercados públicos, lugares en donde las prácticas de manejo y manipulación de este alimento son desconocidas o poco practicadas, lo que puede conllevar a un foco de proliferación de la enfermedad (Ministerio de protección social y Unidad de Evaluación de Riesgos para la Inocuidad de los Alimentos, 2011).

\section{Marco teórico}

\section{Enfermedades trasmitidas por alimentos (ETA)}

Son un grupo de afecciones que se originan a partir de la ingestión de alimentos o el agua, que contienen agentes etiológicos en cantidades que pueden comprometer la salud de un individuo o una población. Entre las enfermedades trasmitidas por alimentos encontramos las infecciones alimentarias producidas por virus, parásitos o bacterias que infectan la luz intestinal por diversas vías, y las intoxicaciones 
alimentarias producidas por la ingestión de toxinas producidas por tejido vegetal, animal o alguna sustancia química (Ministerio de salud y protección social, 2013). (Tabla 1).

Las variedades de Salmonella enterica son la segunda causa más común de gastroenteritis en Australia. Los brotes de infección por Salmonella suelen estar relacionados con los alimentos, especialmente los que contienen carne de pollo y huevos. Varios países europeos han introducido intervenciones basadas en los sistemas de vigilancia de Salmonella en la industria alimentaria, lo que ha llevado a una disminución posterior de las tasas de notificación en humanos. La carne y los huevos de aves de corral son fuentes potenciales de la introducción de una gama definida de patógenos humanos en las cocinas de Australia del Sur. La vigilancia sistemática en curso de los animales y sus productos alimenticios, a nivel de granja y venta al por menor para Salmonella podría proporcionar una prueba más definitiva de los vínculos entre las fuentes de alimentos y las infecciones humanas; y también permiten una medición precisa de las intervenciones tomadas para reducir las tasas de aislamiento de Salmonella en alimentos de origen animal (Fearnley et al; 2011).

Tabla 1. Principales Enfermedades de Transmisión Alimentaria.

\begin{tabular}{|c|c|}
\hline Infecciones alimentarias & Intoxicaciones alimentarias \\
\hline $\begin{array}{ll}\text { Bacterias: } \\
\text { - } \\
\text { - } & \text { Salmonella spp. } \\
\text { - } & \text { Shiguella spp. } \\
\text { - } & \text { Escherichia coli. } \\
\text { - } & \text { Yersinia enterocolitica. } \\
\text { - } & \text { Vibrio spp. } \\
\text { - } & \text { Listeria monocytogenes. }\end{array}$ & $\begin{array}{l}\text { Bacterias: } \\
\text { - } \quad \text { Toxina producida por Clostridium perfringens. } \\
\text { - } \quad \text { Estafilienterotoxicosis. } \\
\text { - } \quad \text { Teurotóxicas botulínicas. } \\
\text { - } \quad \text { oxina producida por Bacilus cereus. }\end{array}$ \\
\hline $\begin{array}{l}\text { Parásitos: } \\
\begin{array}{ll}\text { - } & \text { Amebiasis. } \\
\text { - } & \text { Giardiasis. } \\
\text { - } & \text { Toxoplasmosis. } \\
\text { - } & \text { Ascariasis. } \\
\text { - } & \text { anisaquiasis. } \\
\text { - } & \text { triquinelosis. } \\
\text { - } & \text { teniasis. } \\
\text { - } & \text { cisticercosis. } \\
\text { - } & \text { hidatidosis. } \\
\text { - } & \text { fasialosis. }\end{array}\end{array}$ & $\begin{array}{l}\text { Hongos: } \\
\text { - } \quad \text { Micotoxicosis. }\end{array}$ \\
\hline $\begin{array}{l}\text { Virus: } \\
\text { - } \quad \text { Hepatitis A. } \\
\text { - } \quad \text { Virus de Norwalk. } \\
\end{array}$ & $\begin{array}{l}\text { Biotoxinas: } \\
\text { - } \quad \text { Intoxicación paralizante por moluscos (PSP). } \\
\text { - } \quad \text { Intoxicación diarreica por moluscos (DSP). }\end{array}$ \\
\hline $\begin{array}{l}\text { Priones: } \\
\text { - Enfermedad de Creutzfeldt-Jakob. }\end{array}$ & - Intoxicación neurotoxica por moluscos (NSP). \\
\hline
\end{tabular}

Fuente: Pascual (2005)

\section{Infecciones alimentarias producidas por bacterias.}

Dentro de las infecciones alimentarias, las bacterias son los organismos encontrados con mayor frecuencia debido a su capacidad reproductiva y la versatilidad de medios que pueden llegar a tolerar, las infecciones 
provocadas por estos organismos se dan principalmente por la colonización de bacterias con capacidad infectiva en la luz intestinal del individuo que ingiere dicho alimento o por la absorción de exotoxinas producidas estas bacterias aunque esto es considerado una intoxicación alimentaria y no una infección (Pascual M, 2005).

En el grupo de las infecciones alimentarias producidas por bacterias encontramos de manera frecuente: salmonelosis, campilobacteriosis, shigelosis, infecciones por Escherichia coli enteroinvasivo/ enterohemorrágico, yersioniosis, cólera (Heymann, 2005).

\section{Enfermedades bacterianas trasmitidas por pollo.}

La carne de pollo es actualmente una alternativa alimenticia con alta demanda, por ser una fuente de proteína animal barata y con excelente sabor. Una muestra de esto es que en el 2015 la producción de pollo a nivel mundial fue de 97.2 millones de toneladas, un $4 \%$ mayor que en el 2014 y se prevé que en el año 2016 aumente esta cantidad (Pérez, 2016). En Colombia la producción de pollo en el 2015 fue de un 1.424.388 de toneladas de pollo y un aumento significativo en la producción desde el 2012. En el departamento del Cesar la producción de pollos se concentra en 60 granjas avícolas con capacidad de encasetamiento de 414.497, representando un producto indispensable para la canasta familiar en todo el país y específicamente en el departamento (Master, 2106). (Figura 1).

Esta carne tiene características que facilitan la producción de infecciones de diversos microorganismos en donde las bacterias juegan un papel muy importante.

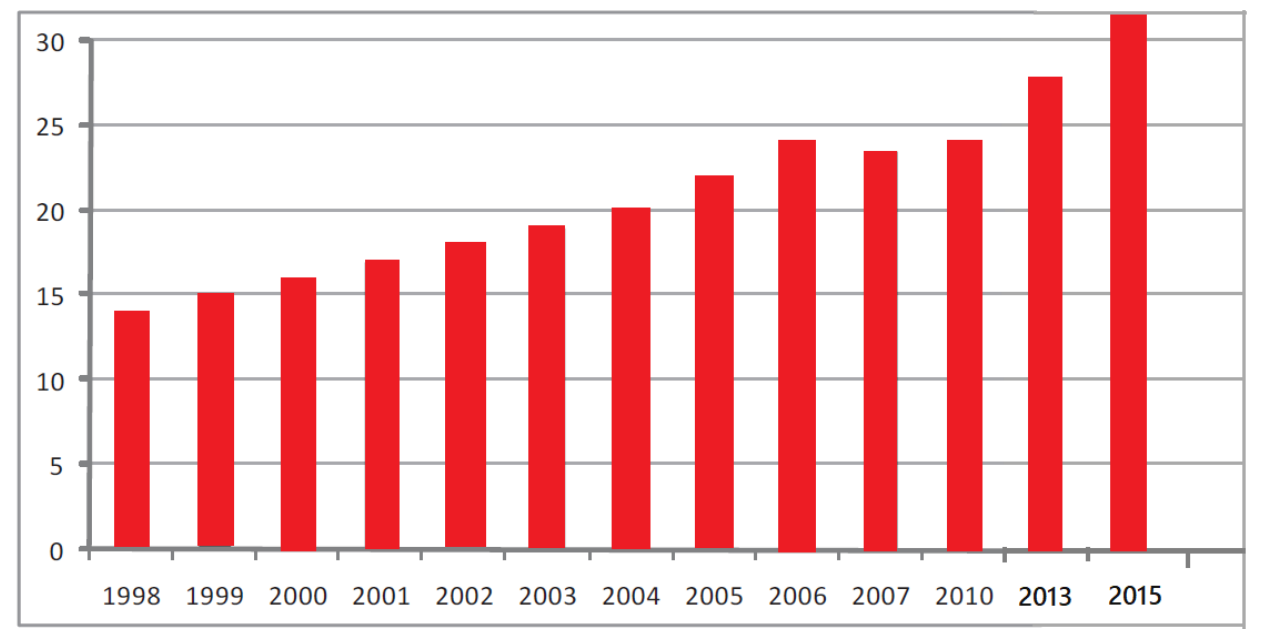

Figura 1. Consumo per cápita de pollo Kg/persona/año en Colombia. (2000-2015).

Fuente: Modificado de (Ministerio de protección social y EURIA, 2011; Federación Nacional de Avicultores de Colombia, 2016).

Las poblaciones bacterianas que podemos encontrar en los canales del pollo están determinadas por la biota intestinal de cada ave, las malas técnicas de sacrificio además de ambientes insalubres, técnicas de crianza deficientes entre otros factores contribuyen a las infecciones en la carne de pollo producida y comercializada (Castañeda et al, 2013).

Entre las bacterias con capacidad infectiva en carne de pollos encontramos: Salmonella spp., Campylobacter spp., Staphylococcus aureus, Vibrio spp., Pasteurella multocida, Clostridium botulinum, Clostridium perfringens, Erysipelothrix rhusiopathiae, Riemerella anatipestifer, Listeria monocytogenes, 
Mycoplasma gallisepticum, Mycoplasma synoviae, Escherichia coli O157: H7 y Yersinia enterocolitica. Las más frecuentes capaces de producir hasta el 90\% de los casos de ETA's en pollos son: Salmonella, Campylobacter spp., Escherichia coli (O157: H7) y Listeria monocytogenes (Eberle y Kiess, 2012).

\section{Salmonelosis}

La salmonelosis es el nombre dado a el grupo de enfermedades producidas por la bacteria Salmonella spp., esta afección se divide en dos grupos, la salmonelosis que causa la fiebre tifoidea y la salmonelosis que cursa con síndromes gastrointestinales, siendo esta ultima la más común, las cuales tienen unas características que la hacen sobrevivir en ambientes óptimos. (Tabla 2). (Ministerio de protección social y EURIA, 2011).

\section{Agente etiológico}

Salmonella spp., es un bacilo Gram negativo, anaerobio facultativo perteneciente a la familia Enterobacteriaceae, en la actualidad se reconocen más de 2700 serovares. Móviles por la presencia de flagelos peritricos, con excepción de la serovariedad Gallinarum-Pollorum (Brunia, 2008).

El género Salmonella se divide en dos especies: Salmonella enterica y Salmonella bongori (Grupo V) (Corburn et al, 2007). Siendo la subespecie enterica capaz de producir hasta el $99 \%$ de la salmonelosis tifoidea y no-tifoidea (Ellermeier y Slauch, 2006). Por la gran diversidad de serovares identificados, la Organización Mundial de la Salud (OMS) propuso la clasificación basada en el sistema Kauffman-White, este modelo propone la división respecto a los antígenos que posee: flagelar $(\mathrm{K})$, capsular $(\mathrm{H})$ y somático (O) (Braden et al, 2006).

Tabla 2. Características del genero Salmonella.

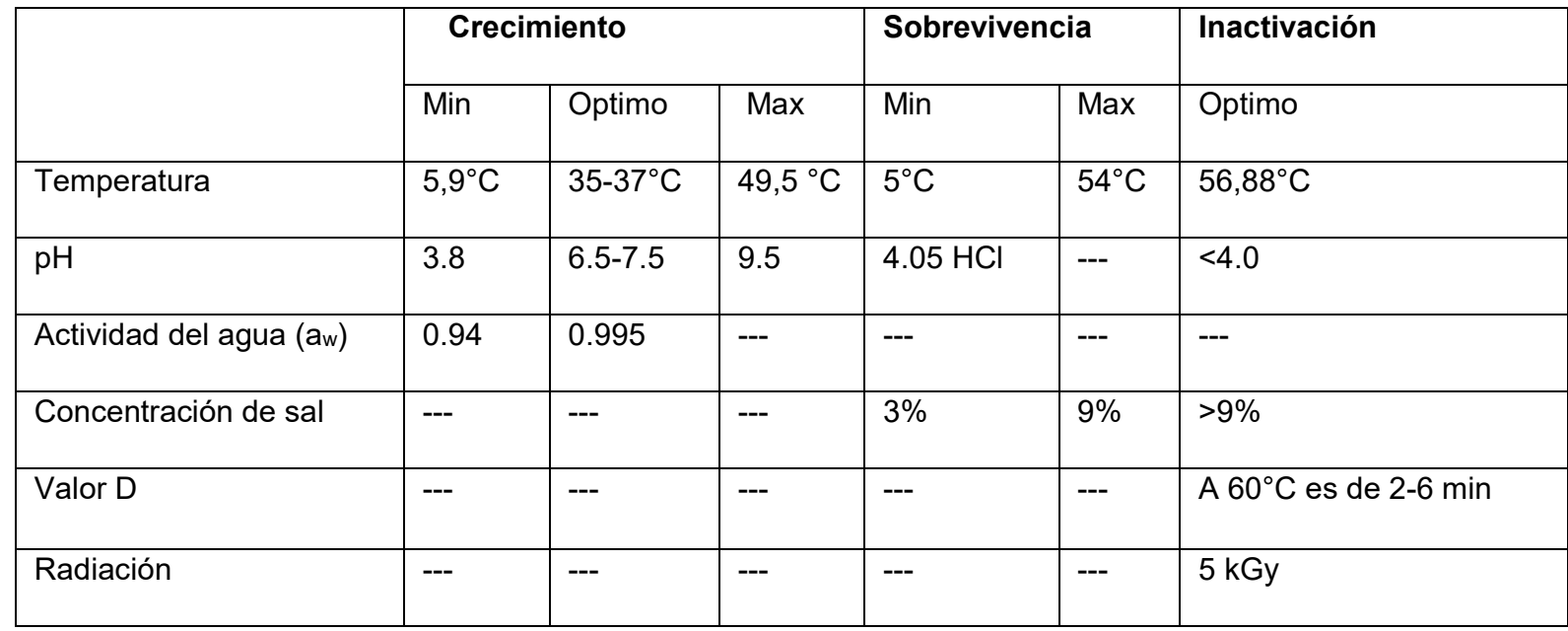

Fuente: Ministerio de protección social y EURIA, (2011).

\section{Patogenia}

La principal vía de entrada de Salmonella es la oral, al tener contacto con heces de animales con la infección. La dosis de la bacteria que puede llegar a causar Salmonelosis depende de varios factores, como: el grado de resistencia del huésped, personas con disminución del sistema inmune, el tipo de alimento, y el estado fisiológico del microorganismo. La dosis infectiva para humanos está entre $10^{6}-10^{8}$ células, aunque otros estudios epidemiológicos señalan una dosis infectiva de solo 10 células (Humphrey, 2004). 
La bacteria puede colonizar el intestino delgado debido a su resistencia al pH del estómago, sales biliares y peristaltismo, luego pasa a invadir los ganglios linfáticos mesentéricos, produciendo una infección localizada. Salmonella puede elidir los sistemas de defensas intracelulares de las células intestinales y empezar su ciclo de división dentro de la célula. De tratarse de una infección de los serovares S. Typhi y S. Paratyphi, pasa al torrente sanguíneo y produce una infección sistémica, multiplicándose dentro de los macrófagos, y ubicándose en médula ósea, hígado, bazo, etc. Sale del organismo por medio de las heces, el $1 \%$ de los adultos infectados y el $5 \%$ de los niños menores de 5 años pueden excretar el microorganismo por más de un año, llegando a contaminar a los alimentos donde presenta una gran resistencia (Ministerio de protección social y EURIA, 2011).

\section{Salmonelosis Tifoidea}

La salmonelosis tifoidea, produce el grupo de enfermedades denominadas fiebres entéricas, dentro de las cuales encontramos la fiebre tifoidea producida por Salmonella typhi y la fiebre paratifoidea producida por Salmonella paratyphi A, B, o C. ambas enfermedades cursan con similitudes patológicas (infecciones sistémicas) y clínicas, siendo más fuerte la fiebre tifoidea (Wain et al, 2015).

\section{Epidemiología}

Alrededor de inicios del siglo XX la fiebre tifoidea se consideraba endémica en muchos países, pero las mejoras en diversos métodos de sanidad lograron controlar la infección en diversos países. Con pocas excepciones, hace años que esta enfermedad no causa muertes en las regiones de Europa Occidental, Canadá y Estados Unidos. En la mayoría de los casos reportados son atribuidos a la llegada de la enfermedad por personas infectadas desde el extranjero (Instituto Nacional de Salud, 2010).
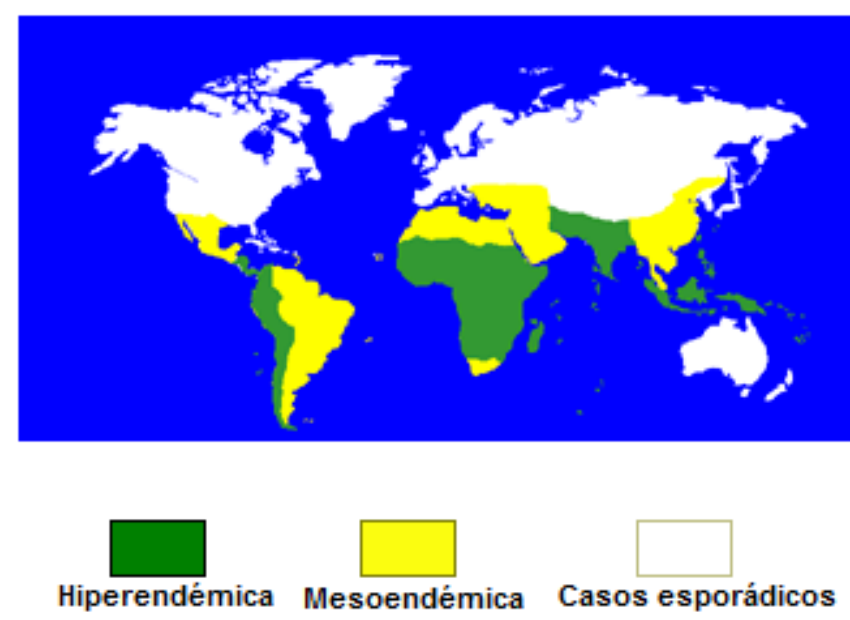

Figura 2. Grado endémico mundial de la fiebre tifoidea.

Fuente: Modificado de (Asociación de Médicos de Sanidad Exterior, 2016)

Es difícil saber la realidad de las fiebres entéricas en los países subdesarrollados, aun así, se consideran importantes problemas de salud pública. Un ejemplo claro de esto fue el brote ocurrido en el 2011-2012 en Zimbawe, con unos 4.000 casos sospechosos (y más de 1.800 oficialmente notificados) de esta enfermedad, el brote más reciente fue en el 2015 en Uganda se reportaron 1940 casos sospechosos. La OMS estima que se producen 21 millones de casos/año, con entre un 1 y un $4 \%$ (200.000 a 600.000) de casos fatales en el mundo, aunque el $85 \%$ de los casos se dan en los países de India, Bangladesh y 
Pakistán. Se debe considerar los casos leves y tratados que no son notificados, esto genera una infraestimación de la enfermedad en ciertas zonas del mundo (Organización Mundial de la Salud, 2016).

En Colombia, entre los años 2002 y 2004 se reportaron 2.330 casos al Sistema de Vigilancia en Salud Pública (Sivigila), sólo 3,7\% se confirmaron por el laboratorio de elección, lo que dificulta la caracterización de la enfermedad en este país (Solarte, 2009). Los datos arrojados por el Sivigila (2016) en su semana epidemiológica 42, indican 229 casos probables y 192 casos comprobados de la enfermedad siendo los departamentos de Norte de Santander, Antioquia, Meta y el Chocó donde se presentó mayor incidencia (Sistema de Vigilancia en Salud Pública, 2016).

\section{Manifestaciones clínicas}

S. typhi y $S$. paratyphi tienen un periodo de incubación de dos semanas, aunque este periodo puede variar de una semana a un mes, a partir de la ingestión de la bacteria por medio de agua o alimentos contaminados. S. typhi y $S$. paratyphi invaden al organismo atreves de las células $M$ del intestino, pertenecientes al tejido linfoide. Aunque la anterior apreciación aún no se ha podido comprobar por la imposibilidad de cultivar células $\mathrm{M}$ en el laboratorio, se presume de su papel por experimentos realizados con células epiteliales y macrófagos, siendo estos un eslabón en el proceso de invasión (Parra,et.al, 2002).

La diarrea no siempre se presenta, por lo general hay ulceraciones. $S$. typhi se multiplica en el epitelio de la submucosa, luego llega al torrente circulatorio donde se dispersa por el todo el cuerpo. Se multiplica nuevamente en el bazo e hígado, para luego liberarse en grandes cantidades al torrente sanguíneo. Dicha septicemia puede confirmarse por el cultivo de la bacteria de la sangre, esto refleja una bacteriemia. La duración de este estadio de la infección varía entre 2 y 3 semanas. La tos seca, la fiebre alta e intensos dolores de cabeza son síntomas característicos de este estadio. La temperatura del cuerpo puede variar por las tardes, acompañadas por escalofríos delirios y convulsiones (Quesada, et, al. 2016).

Los desenlaces fatales por fiebre tifoidea ocurren principalmente por la ruptura del bazo, ocasionando un choque séptico producido por el LPS, este estimula la liberación de las citosinas. Se pueden dar casos en que los individuos se comporten como portadores sanos, continuamente excretando las bacterias del bazo, aunque la incidencia se estima en un 10\% (Calva, 2012).

\section{Salmonelosis no-tifoidea}

Este tipo de afección ocasiona procesos gastrointestinales, siendo la más común de las infecciones alimentarias en muchos países del mundo. Los serovares más comunes son $S$. typhimurium y $S$. enteritidis (Jiménez et al, 2010).

\section{Epidemiologia}

La salmonelosis no-tifoidea por ser una enfermedad que abarca una serie de síntomas muy semejantes a otras infecciones de carácter entérico existe una gran posibilidad que los datos aportados por organismos competentes reflejen solo los datos de hospitalización por dicha patología y no aporten datos concretos de la magnitud de la infección en todo el país (Sistema de Vigilancia en Salud Pública, 2016).

En el caso de Colombia los reportes son generados por organismos como Sistema de Información de Prestaciones de Salud (RIPS) y el Instituto Nacional de Salud (INS) (Tabla 3).

Entre el enero del 2008 hasta agosto del 2010 el Sivigila reporto 102 casos sospechosos en donde se comprobó que el $31.7 \%$ tuvo como agente etiológico Salmonella spp., solo lográndose comprobar 2 casos por $S$. enteritidis y en los 32 casos restantes los serovares no fueron comprobados. A pesar de esto, el 
Grupo de microbiología del INS reportó entre el periodo comprendido entre los años 2005 y 2008 un total de 24 casos en los cuales se estudiaron los serovares implicados, resultando un total de 8 infecciones causadas por $S$. Typhimurium y 6 por $S$. enteritidis. Es importante denotar el aumento que ha tenido el número de casos comprobados de salmonelosis, esto puede deberse a una mejora en la accesibilidad de la población a los sistemas de salud (Ministerio de protección social y EURIA, 2011).

Tabla 3. Incidencia de Salmonelosis en Colombia, 1997 - 2010.

\begin{tabular}{|c|c|c|}
\hline Año & $\begin{array}{c}\text { casos/100.000 } \\
\text { habitantes }\end{array}$ & $\begin{array}{c}\text { No. de casos por } \\
\text { Salmonella }\end{array}$ \\
\hline 1997 & 0,238736094 & 99 \\
\hline 1998 & 0,270085277 & 112 \\
\hline 1999 & 0,306257413 & 127 \\
\hline 2000 & 0,349663975 & 145 \\
\hline 2001 & 0,412362343 & 171 \\
\hline 2002 & 0,607691874 & 252 \\
\hline 2003 & 0,612514826 & 254 \\
\hline 2004 & 0,677624669 & 281 \\
\hline 2006 & 0,815078784 & 338 \\
\hline 2007 & 0,798198454 & 331 \\
\hline 2008 & 1,005585364 & 417 \\
\hline 2009 & 0,964590277 & 400 \\
\hline 2010 & 1,560224773 & 647 \\
\hline
\end{tabular}

Fuente: tomado de (Ministerio de protección social y EURIA, 2011).

Guerra et al (2014) realizó una investigación en el departamento de Nariño, hallando una prevalencia de $34 \%$ respecto a la presencia de Salmonella spp. en expendios de productos cárnicos en todo el departamento, concluyendo que pesar de la vigilancia epidemiológica y de que los establecimientos cuentan con los permisos sanitarios, se incumplen las medidas sanitarias y hay una considerable presencia de Salmonella spp.

\section{Manifestaciones clínicas}

La enfermedad se caracteriza por una gastroenteritis que causa diarreas (hasta 20 evacuaciones en 24 horas), fiebre, dolor abdominal, dolor de cabeza; en los últimos años se han reportado diarreas con sangre (Corburn et al 2007), también pueden producir síntomas como fatiga, dolor muscular, cansancio y somnolencia (Jay, et, al. 2005). La enfermedad tiene una media de duración de 7 días (3-20 días dependiendo de ciertas variables (Kimura et al, 2004). Se han reportado casos de bacteriemias en otras partes del cuerpo (Ellermeier y Slauch, 2006).

S. Typhimurium al parecer causa una enfermedad, se trata de una infección sistémica seria en niños e individuos inmunocomprometidos (Jay, et; at. 2005). Se han reportado casos de endocarditis, principalmente en donde existen anomalías de las válvulas; también puede causar aneurismas aórticos, estas infecciones tienden a tener una alta tasa de mortalidad (Fernández et; al. 2004).

\section{Detección de Salmonella en alimentos}

\section{Cultivo en medios selectivos e identificación bioquímica}


El aislamiento del género Salmonella se realiza a través de medios de cultivo selectivos y diferenciales como Hektoen, XLD, Bismuto sulfito y un conjunto de pruebas bioquímicas. (González et al., 2014). La identificación bioquímica de Salmonella permite caracterizar las colonias consideradas como sospechosas teniendo en cuenta el metabolismo del género bacteriano, de acuerdo a la (Asociación de las comunidades analíticas" AOAC, 2011), consta principalmente de las siguientes pruebas:

Triple Azúcar Hierro (TSI): Reacción alcalina ácido con producción de $\mathrm{H}_{2} \mathrm{~S}$. Se evidencia fondo negro del tubo y con o sin producción de gas.

LIA: Reacción K/K. Se observa un cambio en la coloración a púrpura de todo el medio, producción de $\mathrm{H}_{2} \mathrm{~S}$ y gas por la acción de la enzima Lisina descarboxilasa.

CITRATO DE SIMMONS. Utilización de citrato como fuente de Carbono evidenciándose un cambio en la coloración del medio. (Asociación de las comunidades analíticas” AOAC, 2011).

\section{Técnicas Inmunoenzimáticas}

Algunos equipos basados en técnica inmunoenzimática para la detección de Salmonella spp. son: El equipo automatizado MiniVIDAS $®$, que permite la detección de Salmonella spp. en muestras de alimentos de forma rápida, sensible y rentable. Estos métodos facilitan una reacción de anticuerpos con los antígenos bacterianos, detectando la presencia de Salmonella en alimentos (Biomerieux, 2012).

\section{Técnicas moleculares}

Se basan en la amplificación de regiones específicas de ADN in vitro, lanzando resultados altamente sensibles, específicos y reproducibles. Ejemplos de este método son la secuenciación y la reacción en cadena de la polimerasa (PCR), la cual se fundamenta en la síntesis de nuevas hebras de ADN a partir de una molde, que por acción de proteínas y variables físicas como la temperatura, permiten la extensión del material genético aumentando exponencialmente la cantidad de copias del fragmento de interés (Innis et al., 2012), siendo ampliamente utilizado en múltiples estudios (Yánez, et al., 2008; Acosta et al., 2013; González, et al;2004 ). En términos de sensibilidad y especificidad, la técnica PCR se desarrolla de forma favorable en comparación con técnicas tradicionales de identificación microbiológica (Rodríguez, 2013).

\section{Contexto de la investigación}

El desplazamiento de personas del campo a las ciudades, el desempleo y las pocas medidas de control en las plazas de mercado y sitios de expendio han generado una proliferación de puestos de ventas de alimentos callejeros con pocas medidas de higiene y control sanitario totalmente expuestos a la contaminación, lo cual pone en riesgo la salud de las personas

La Primera conferencia europea sobre calidad e inocuidad de los alimentos y las enfermedades transmitidas por los alimentos, manifiestan que los alimentos son la fuente principal de exposición a agentes físicos (cuerpos extraños), químicos (plaguicidas, fungicidas, medicamentos) o biológicos (bacterias, hongos, virus, parásitos); esta contaminación lleva o conduce a riesgos sustanciales para la salud de los consumidores y representa grandes cargas económicas para las diversas comunidades y naciones. Un alimento inocuo es aquel que no genera efectos adversos sobre la salud, ni en la calidad de vida del consumidor, ni presenta riesgos físicos, químicos o biológicos (Food and Agriculture Organization of the United Nations (2004)

Ante esta realidad el presente documento aborda un trabajo de investigación que detecto Salmonella spp. en carne de pollo crudo, vendidas en expendios de diferentes barrios de la ciudad de Valledupar, mediante 
la normativa colombiana que regula el proceso de detección de Salmonella spp. en alimentos, mostrando así la relevancia de la bacteria en el producto vendido a la comunidad.

\section{Materiales y Métodos}

\section{Área de estudio}

Esta investigación se llevó a cabo en las 6 comunas de la zona urbana del Municipio de Valledupar-Cesar, zona de interés epidemiológico por tener la mayor parte de la población en el municipio de Valledupar ( Figura 3), Ciudad capital del Departamento del Cesar, situada en la margen occidental del Río Guatapuri al pie de las últimas estribaciones de la Sierra Nevada de Santa Marta a los $10^{\circ} 29^{\prime}$ latitud norte y $73^{\circ} 15^{\prime}$ de longitud al oeste de Greenwich, está a 169 metros sobre el nivel del mar; su temperatura media es de $28^{\circ} \mathrm{C}$.

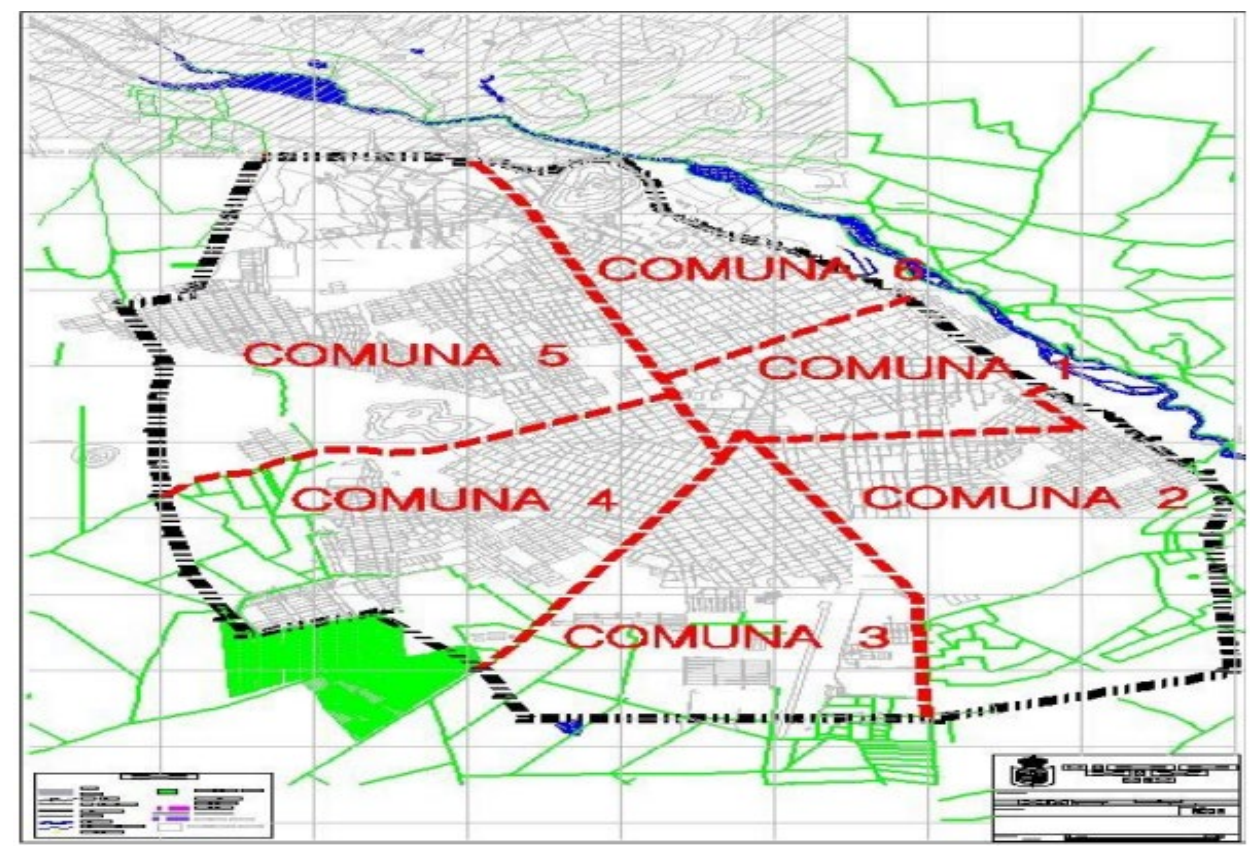

Figura 3. Área de estudio para la recolección de las muestras en carne de pollo en expendios de la Ciudad de Valledupar. Cesar. Colombia.

\section{Recolección de las Muestras}

Se realizó un muestreo aleatorio de 100 muestras en expendios formales e informales de carne de pollo en las 6 comunas de la ciudad de Valledupar. Se determinó la temperatura del lugar de almacenamiento, la parte del animal que se analizó y el proveedor de carne de pollo (Tabla 4). Las muestras eran donadas o compradas dependiendo de la accesibilidad que prestara el encargado de dicho expendio, estas fueron cortadas y seleccionadas por el tendero, se introducían en bolsas de cierre hermético, las cuales se rotulaban con un número de identificación, posteriormente se guardaban en una cava de polietileno que contenían pilas refrigerantes para ser llevadas al laboratorio de Microbiología de la Universidad Popular del Cesar para su procesamiento. 
Tabla 4. Indicadores de información para la recolección de las muestras en carne de pollo en expendios de la Ciudad de Valledupar, Cesar, Colombia.

\begin{tabular}{|c|c|c|c|c|c|c|}
\hline CODIGO & NOMBRE & $\begin{array}{l}\text { PARTE } \\
\text { DEL } \\
\text { ANIMAL }\end{array}$ & $\begin{array}{c}\text { CONDICION DE } \\
\text { REFRIGERACION }\end{array}$ & PROVEEDOR & COMUNA & BARRIO \\
\hline 7 & $\begin{array}{c}\text { Provisiones } \\
\text { Leidis Tatiana }\end{array}$ & Muslo & $<0^{\circ} \mathrm{C}$ & MERCADO & 1 & Kennedy. \\
\hline 8 & $\begin{array}{l}\text { Aquí me trajo } \\
\text { el Rio }\end{array}$ & Pechuga & $<4^{0 C}$ & MERCADO & 1 & $\begin{array}{c}\text { SAN } \\
\text { JORGE. }\end{array}$ \\
\hline 11 & $\begin{array}{c}\text { Provisiones } \\
\text { ERI }\end{array}$ & Pechuga & $0-4^{\circ} \mathrm{C}$ & PUROPOLLO & 2 & Villa Clara \\
\hline 12 & Los pelaos & Pechuga & $>4^{\circ} \mathrm{C}$ & CAMPOLLO & 2 & San Jorge \\
\hline 18 & $\begin{array}{l}\text { Provisiones } \\
\text { Kenis }\end{array}$ & Muslo & $>4^{\circ} \mathrm{C}$ & MAXPOLLO & 2 & $\begin{array}{l}\text { Villa del } \\
\text { Rosario }\end{array}$ \\
\hline 24 & $\begin{array}{c}\text { La esquina de } \\
\text { Santi }\end{array}$ & Pechuga & $>4^{\circ} \mathrm{C}$ & MAXPOLLO & 3 & San Martin \\
\hline 28 & $\begin{array}{l}\text { Provisiones } \\
\text { William }\end{array}$ & Pechuga & $0-4^{\circ} \mathrm{C}$ & MERCADO & 3 & Villa Leonor \\
\hline 32 & $\begin{array}{c}\text { La preferidad } \\
\mathrm{N}^{\circ} 3\end{array}$ & Muslo & $0-4^{\circ} \mathrm{C}$ & CAMPOLLO & 3 & $\begin{array}{l}\text { Primero de } \\
\text { Mayo }\end{array}$ \\
\hline 34 & los estoraques & Muslo & $0-4^{\circ} \mathrm{C}$ & MERCADO & 3 & $\begin{array}{l}\text { Primero de } \\
\text { Mayo }\end{array}$ \\
\hline 37 & La 44 & Pechuga & $<0^{\circ} \mathrm{C}$ & MAXPOLLO & 3 & $\begin{array}{c}\text { La } \\
\text { Manuelita }\end{array}$ \\
\hline 44 & Casa Blanca & Pechuga & $>4^{\circ} \mathrm{C}$ & MAXPOLLO & 3 & $\begin{array}{c}\text { Don } \\
\text { Carmelo }\end{array}$ \\
\hline 72 & La Primavera & Pechuga & $>4^{\circ} \mathrm{C}$ & MERCADO & 4 & $\begin{array}{c}\text { Jorge } \\
\text { Dangond. }\end{array}$ \\
\hline 76 & $\begin{array}{l}\text { Provisiones la } \\
\text { clínica }\end{array}$ & Pechuga & $>4^{\circ} \mathrm{C}$ & CAMPOLLO & 4 & $\begin{array}{c}\text { Los } \\
\text { Caciques. }\end{array}$ \\
\hline 99 & Las tres $\mathrm{J}$ & Pechuga & $>4^{\circ} \mathrm{C}$ & MERCADO & 5 & $\begin{array}{l}\text { Cinco de } \\
\text { Enero }\end{array}$ \\
\hline 100 & $\begin{array}{l}\text { Mercado buen } \\
\text { precio }\end{array}$ & Pechuga & $>4^{\circ} \mathrm{C}$ & MERCADO & 5 & Garupal \\
\hline 52 & $\begin{array}{l}\text { Provisiones } \\
\text { Andrea }\end{array}$ & Pechuga & $0-4^{\circ} \mathrm{C}$ & MERCADO & 6 & Guajira \\
\hline
\end{tabular}




\begin{tabular}{|c|c|c|c|c|c|c|}
\hline 60 & $\begin{array}{c}\text { El Poder de } \\
\text { Dios }\end{array}$ & Pechuga & $0-4^{\circ} \mathrm{C}$ & $\begin{array}{c}\text { TODO } \\
\text { CRIOLLO }\end{array}$ & $\begin{array}{c}\text { San } \\
\text { Joaquín }\end{array}$ \\
\hline 61 & $\begin{array}{c}\text { Miscelánea } \\
\text { Muver }\end{array}$ & Pechuga & $<0^{\circ} \mathrm{C}$ & CAMPOLLO & 6 & $\begin{array}{c}\text { San } \\
\text { Joaquín. }\end{array}$ \\
\hline
\end{tabular}

\section{Procesamiento de las Muestras}

El procesamiento de las muestras se hizo acorde a la Norma Técnica Colombiana 4574 (Icontec, 2007), que consiste en 4 etapas:

\section{Prenriquecimiento en medio liquido no selectivo}

La muestra fue cortada con pinzas de disección estériles y puestas en cajas de Petri para su pesaje, al obtener 25 gramos de la muestra, se introdujo en un mortero estéril para macerar la muestra.

Los 25 gramos de muestra macerada se introdujeron en 225 mililitros de agua peptonada tamponada contenida en frascos de tapa ancha, se incubó a $37^{\circ} \mathrm{C} \pm 1^{\circ} \mathrm{C}$ por $18 \mathrm{~h}+/ 2$ horas.

\section{Enriquecimiento en medio liquido selectivo}

Esperadas las 18 horas, se sacaron de las incubadoras los recipientes con agua peptonada, de los cuales se extrajo 0.1 mililitros para inocularlo en 10 mililitros de caldo Rappaport Vassiliadis (medio RVS). Este medio se incubó a $41,5^{\circ} \mathrm{C} \pm 1,0{ }^{\circ} \mathrm{C}$ durante $24 \mathrm{~h} \pm 3$ horas.

\section{Siembra en medio selectivo}

Transcurrido el tiempo de incubación se extrajo el recipiente con el caldo RVS, a partir de este caldo se inoculó en el medio solidoXilosa Lisina Desoxicolato (XLD) el cual se incubó a $37^{\circ} \mathrm{C} \pm 1^{\circ} \mathrm{C}$, esperada las $24 \pm 3$ horas se vieron los resultados, las colonias negras son presuntivas para Salmonella spp.

\section{Selección de colonias para su confirmación}

Las colonias negras presentes en los medios XLD fueron seleccionadas e inoculadas en agar nutritivo que se incubó a $37^{\circ} \mathrm{C}$ durante 24 horas.

\section{Confirmación por pruebas bioquímicas}

Se realizó una batería bioquímica de 6 componentes en total: Citrato, Lisina Hierro Agar (LIA), Sulfuro, Indol, Motilidad (SIM), -Urea, Voges - Proskauer (VP), Triple azúcar hierro (TSI). Esta pila de pruebas bioquímicas se incubó a $37^{\circ} \mathrm{C}$ por $24 \mathrm{~h} \pm 3$ horas. (Tabla 5). Posterior a esto se leyeron los resultados; estos se reportaron como presencia o ausencia de Salmonella spp. 
Tabla 5. Resultados positivos para Salmonella spp. en pila de pruebas bioquímicas en carne de pollo en expendios de la ciudad de Valledupar, Cesar, Colombia

\begin{tabular}{|l|l|}
\hline \multicolumn{1}{|c|}{ Prueba bioquímica } & \multicolumn{1}{c|}{ Resultados } \\
\hline Lisina Hierro Agar (LIA). & Purpura intenso/ ennegrecimiento/ fondo amarillo. \\
\hline Sulfuro, Indol, Motilidad (SIM). & $\begin{array}{l}\text { Crecimiento en superficie y picadura, turbiedad/difusión fuera de } \\
\text { picadura/ ennegrecimiento. }\end{array}$ \\
\hline Urea. & No hay viraje. \\
\hline Voges - Proskauer (VP). & Con reactivos VP1 y VP2: Anillo rojizo. \\
\hline Triple azúcar hierro (TSI). & Fondo tubo amarillo/ ennegrecimiento. \\
\hline Citrato. & Vira color azul. \\
\hline
\end{tabular}

\section{Tinción de Gram}

En un portaobjetos se añadió una gota de solución salina a la cual se le agregó una pequeña porción de la muestra que creció en el agar nutritivo, se revolvió hasta homogenizar, se esperó hasta secar y se fijó pasándolo por la llama del mechero, posteriormente a esto se le agregó cristal violeta hasta cubrir toda el portaobjetos, se esperó 1 minuto, se enjuagó con agua y se procedió a añadir lugol hasta cubrir todo el portaobjetos, se esperó 1 minuto, se procedió a enjuagar con agua, se añadió alcohol cetona, se esperó 30 segundos y se enjuagó, se adicionó safranina hasta cubrir el porta objetos, pasados el minuto se enjuagó y se dejó secar. Cuando el portaobjetos ya teñido se secó, se procedió a mirar al microscopio añadiendo aceite de inmersión, con el objetivo en 100X, se realizó la identificación microscópica.
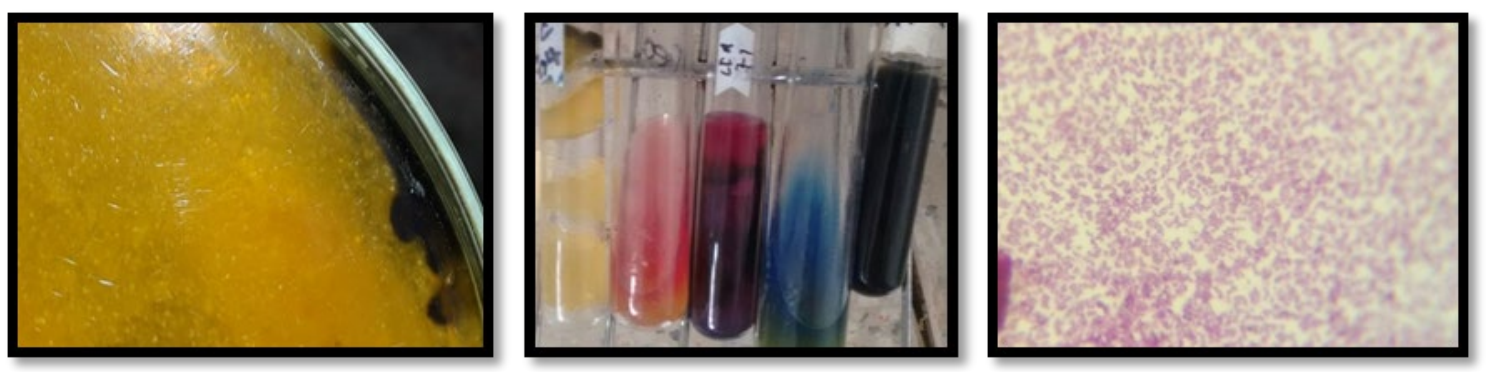

Figura 4. a. colonias presuntivas de Salmonella spp. en medio XLD. b. Pila de pruebas bioquímicas positivas para Salmonella spp. c. bacilos Gram positivos, tinción de Gram de las colonias aisladas.

\section{Resultados}

Se analizaron un total de 100 muestras de carne de pollo, tomadas al azar, procedentes de las 6 comunas de la ciudad de Valledupar. De estas se obtuvo un total de 17 muestras positivas con Salmonella spp. lo 
que representa un $17 \%$ del total de la muestra, y se obtuvieron 63 muestras negativas lo que representa el $63 \%$ de la muestra (Tabla 6 ).

Tabla 6. Resultados por comunas de las muestras en carne de pollo en expendios de la ciudad de Valledupar, César, Colombia.

\begin{tabular}{|c|c|c|c|c|}
\hline $\begin{array}{c}\text { \# de } \\
\text { Comunas }\end{array}$ & $\begin{array}{c}\text { \# de presencia } \\
\text { positiva para } \\
\text { Salmonella spp }\end{array}$ & $\begin{array}{c}\text { \% positivos para } \\
\text { Salmonella spp }\end{array}$ & $\begin{array}{c}\text { \# de } \\
\text { muestras }\end{array}$ & $\begin{array}{c}\text { \% positivos para } \\
\text { Salmonella spp por } \\
\text { comuna }\end{array}$ \\
\hline 1 & 1 & $5,88 \%$ & 20 & $5 \%$ \\
\hline 2 & 3 & $17,64 \%$ & 10 & $30 \%$ \\
\hline 3 & 6 & $35,29 \%$ & 28 & $21,40 \%$ \\
\hline 4 & 0 & $0 \%$ & 9 & $0 \%$ \\
\hline 5 & 2 & $11,76 \%$ & 11 & $18,18 \%$ \\
\hline 6 & 5 & $29,49 \%$ & 22 & $22,70 \%$ \\
\hline
\end{tabular}

Las comunas en la que se detectó mayor número de Salmonella spp. en carne de pollo fueron las numero 3 con 6 muestras positivas (35,29\%) y la comuna 6 con 5 muestras positivas $(29,49 \%)$. No se encontró casos positivos en la comuna número 4 .

Teniendo en cuenta el número de muestras analizadas por comuna, se obtuvo una mayor incidencia de Salmonella spp., en carne de pollo en la comuna número 2, con $3(30 \%)$ casos positivos de 10 muestras tomadas, seguida por las comunas 6 y 3 con $22,7 \%$ y $21,4 \%$ respectivamente. (Tabla 6 ).

Los 7 de los casos positivos se encuentran en expendios que se surten del mercado público de la ciudad de Valledupar, pero las muestras tomadas de expendedores mayoristas de carne de pollo no reportaron casos positivos.

La especie con mayor incidencia en las muestras positivas fue Salmonella subespecie entérica con 14 casos, seguida de Salmonela subespecie typhimurium con 2 casos. Se obtuvo un caso en el que no se tiene claridad de cuál puede ser la especie, debido a que existe ambigüedad en las bibliografías investigadas.

Se detectó un número mayor de casos de Salmonella spp. en el segmento de la pechuga $(71,0 \%)$ y un $29 \% 0$ en el segmento del muslo. (Figura 5). Considerando el número de muestras tomadas se evidencia una incidencia del $17,14 \%$ en la pechuga y un $16,16 \%$ de casos positivos en el segmento del muslo. La única especie encontrada en pechuga fue Salmonella subesp. enterica, mientras que en la parte del muslo se encontró dos casos con Salmonella subesp. typhimurium, dos casos con Salmonella subesp. entérica y un caso sin identificar a que especie pertnece. 


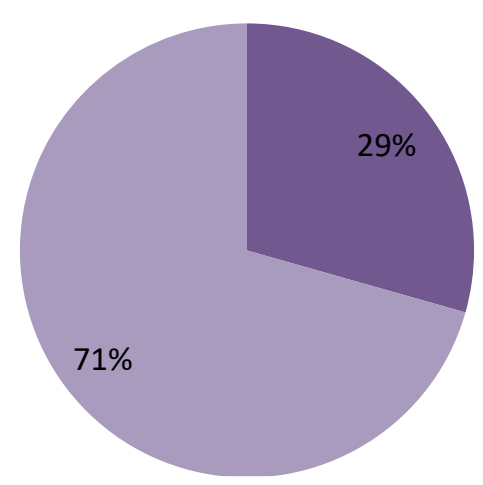

Figura 5. Presencia de Salmonella spp. de acuerdo al segmento de pollo analizado en expendios de la ciudad de Valledupar, César, Colombia

Se evidencia un número de 7 casos positivos con Salmonella subesp. enterica y un caso con Salmonella subesp. typhimurium en carne de pollo almacenada a temperaturas mayores de $4{ }^{\circ} \mathrm{C}$ a esta temperatura, a temperaturas menores de $0^{\circ} \mathrm{C}$ se observaron tres casos con Salmonella subesp. enterica.

Un $62 \%$ de los locales contaban con un sistema de enfriamiento con temperaturas mayores a los $4{ }^{\circ} \mathrm{C}$. Un $24 \%$ se encontraron temperaturas ente $0^{\circ} \mathrm{C}$ y $4^{\circ} \mathrm{C}$ y un $14 \%$ menores o iguales a $0^{\circ} \mathrm{C}$. (Figura 6 ).

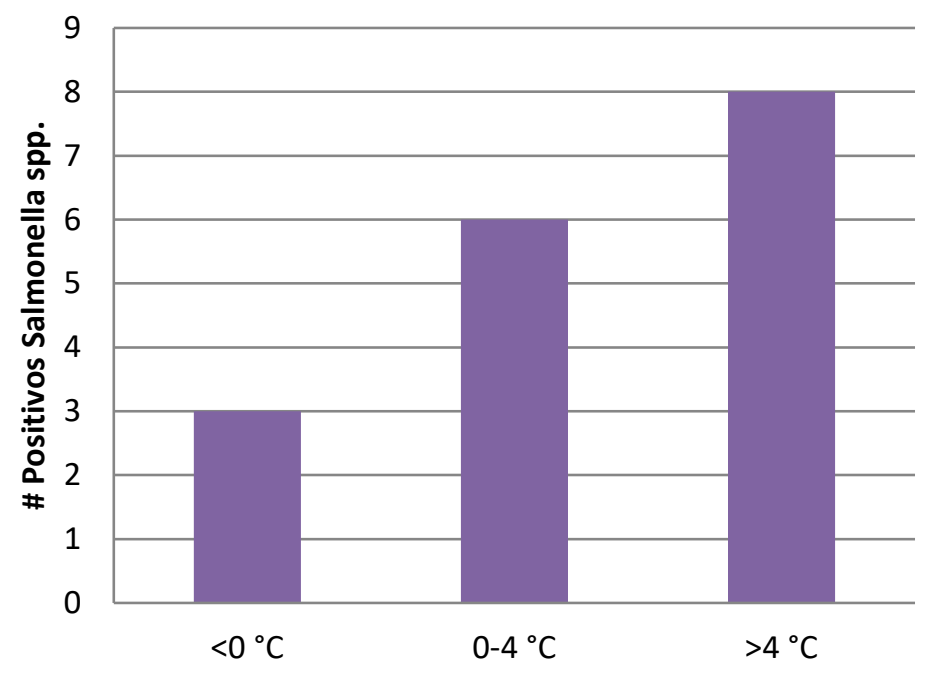

Figura 6. Condiciones de refrigeración vs presencia de Salmonella spp. de las muestras en carne de pollo en expendios de la Ciudad de Valledupar, Cesar, Colombia.

\section{Discusión}

La inocuidad de los alimentos es una necesidad para el mercado actual, las buenas prácticas de producción, procesamiento, trasporte y venta de alimentos como la carne de pollo son cruciales para proveer un producto en óptimas condiciones. Específicamente los centros de venta, uno de los últimos 
eslabones, es un punto crítico en la inocuidad de los alimentos, pues en la mayoría de los casos los vendedores no cuentan con la tecnificación para la manipulación correcta de alimentos como la carne de pollo.

Los resultados obtenidos en la investigación revelan una presencia significativa del $17 \%$ de las muestras estudiadas. Estos datos concuerdan con los reportados por Molina, et al; (2010), en los cuales manifiestan un $20 \%$ de incidencia de Salmonella spp. aislada de pollo crudo comercializado en el área urbana de Mérida, Venezuela de este porcentaje solo se encontró un $22 \%$ de Salmonella subesp. enterica, en contra posición con los datos obtenidos en el estudio, asimismo en el año 2008 se reportó en Bulgaria y Polonia un $26.9 \%$ y $25.5 \%$ respectivamente, casos positivos en canales de pollo (European Food Safety Authority, 2011). Por el contrario, Fearnley et al., (2011) reportaron $38,8 \%$ de casos positivos, al igual que Wilfred, et al; (2010), reportaron un 31.99\% de carne pollo en India y Yen et al., (2012), que reportó 45.9\% de casos de carne de pollo vendidas en mercados minoristas de Vietnam.

Las implicaciones de este resultado son un reflejo de las condiciones sanitarias con que se expende la carne de pollo en lugares de venta formales e informales, como lo señala Guerra et al (2014), demostrando la prevalencia de un $34 \%$ de Salmonella spp. en establecimientos de venta en el Departamento de Nariño, evidenciando de igual forma la presencia de Salmonella en un $100 \%$ de las manos de los vendedores. Asimismo, Silva, et al; (2015), reportan un aumento en la presencia de Salmonella spp. en carnicerías comparándolo con centros de venta exclusivos para productos avícolas, lo que concuerda con lo estipulado en la investigación en donde no se encontraron muestras positivas para los distribuidores mayoristas de productos avícolas. Lo anterior se explica por las condiciones de almacenamiento de los establecimientos, en donde ubican los productos cárnicos, lácteos y avícolas juntos favoreciendo la contaminación cruzada como lo proponen varios autores (Realpe et al, 2016; Gonzales et al, 2010).

Se reportó un número mayor de casos en el segmento de la pechuga, pero considerando el número de muestras escogidas se obtienen datos significativos con un $17,14 \%$ y $16,16 \%$ en pechuga y muslos respectivamente, estos resultados afianzan la idea de una contaminación cruzada, ya sea por el contacto con otros alimentos infectados o por la manipulación del alimento con utensilios, superficies o manos contaminadas.

Las condiciones de enfriamiento es un factor determinante para la proliferación de Salmonella en alimentos, la cadena de frio se ve seriamente afectada en los expendios estudiados tanto formales como informales, encontrando un $62 \%$ de locales que utilizan temperaturas superiores a los $4{ }^{\circ} \mathrm{C}$, estas condiciones no son lo suficientemente aptas como para mantener a los alimentos como la carne de pollo fuera del alcance de múltiples grupos bacterianos que pueden subsistir a estas temperaturas. Además, estas temperaturas pueden ocasionar un deshielo del alimento, produciendo así una contaminación no solo en productos avícolas, si no en todos los productos que se encuentren en el mismo refrigerador, ocasionando así un problema de salud pública (Castañeda et al, 2013).

Salmonella subesp. enterica y Salmonella subesp. typhimurium son dos de los serovariedades con más repercusión en la salud humana (Uribe \& Suarez, 2006). El hallazgo de estas dos especies en las muestras analizas, se torna preocupante para la salud pública de la ciudad de Valledupar, por lo tanto, se requiere una responsabilidad social ambiental que implique no solo el cumplimiento de la norma, sino también el esfuerzo extra, que tiene por objeto la producción limpia, disminuir los impactos al medio ambiente, a los ecosistemas y, por ende, a las comunidades humanas (García J., \& Quintana., L. 2012)

\section{Conclusión}


La incidencia de S. enterica y typhimurium en carne de pollo, se determinó por una cantidad de muestras que fueron tomadas al azar, procedentes de las 6 comunas en la ciudad de Valledupar. La presencia de estos patógenos puede deberse a las condiciones de mal manejo a que son sometido este producto cárnico. En consecuencia, la educación de los empleados, los mayoristas y minoristas sobre la manipulación y almacenamiento adecuados es esencial para prevenir eficazmente la contaminación. Nuestro trabajo ha demostrado la incidencia de estos dos patógenos en productos cárnicos para lo cual se requiere del fortalecimiento y vigilancia, como también de un monitoreo, para la prevención, detección y control de enfermedades transmitidas por los alimentos

\section{Literatura citada}

Adams, R. y Moss, M. (2008). Food microbiology. 3rd Edition. Guildford UK

Alvarado Lagunas, E., Luyando Cuevas, J. R., \& Téllez Delgado, R. (2012). Caracterización del consumidor de la carne de pollo en el área metropolitana de Monterrey. Región y sociedad, 24(54), 175-199. Recuperado de:

http://www.scielo.org.mx/scielo.php?script=sci_arttext\&pid=S1870$39252012000200006 \&$ Ing=es\&tlng=es.

Acosta, L., Pinedo, A., Hernández, E., Villarreal, J. (2013). Comparación de los métodos de inmunoensayo enzimático automatizado (VIDAS) y PCR para la detección de Salmonella spp. en expendios de la ciudad de Santa Marta (Colombia). Saluduninorte. 29 (2): 174-182.

AOAC Official Methods of Analysis (2011). Salmonella in Foods. Identification. AOAC International.

Asociación de Médicos de Sanidad Exterior. (2016). Fiebre Tifoidea. Epidemiología y situación mundial. Amse.es. Recuperado de: http://www.amse.es/index.php?option=com content\&view=article\&id=87:fiebre-tifoideaepidemiologia- $y$-situacion- mundial $\&$ catid $=42$ : inf -epidemiologica $\&$ ltemid $=50$

Biomerieux. (2012). Manual del usuario mini VIDAS ${ }^{2}$.

Bello, L; Ortiz, D.; Pérez, El; Castro, V. (1990). Salmonella en carnes crudas: Un estudio en localidades del Estado de Guerrero. Salud Pública de México, enero-febrero, 74-79.

Braden, C., Fields, P., Bean, N., Tauxe, R. CDC. (2006). Salmonella Annual Summary. Division of Bacterial and Mycotic Diseases. Foodborne and Diarrheal Diseases Branch. Atlanta, Georgia.

Brunia, A. (2008). Foodborne Microbial Pathogens. Ed Springer. USA.

Calva, E. (2012). Salmonella typhi y la fiebre tifoidea: de la biología molecular a la salud pública. Recuperado de: http://www.biblioweb.tic.unam.mx/libros/microbios/Cap4/

Castañeda, M., Braña, D., Rosario, V., Martínez, W. (2013). Calidad Microbiológica de la Carne de Pollo. México.

Coburn B 1, Grassl GA, Finlay BB. (2007). Salmonella, el huésped y la enfermedad: una breve reseña. Immunol Cell Biol. 85 (2): 112-8.

Johnny D, Germán A, Salim M. (2004) Presencia de Salmonella spp. en un área del Caribe colombiano: un riesgo para la salud pública. Revista Biomédica 24 (1). 
Eberle, K. y Kiess, A. (2012). Phenotypic and genotypic methods for typing Campylobacter jejuni and Campylobacter coli in poultry. Poult. Sci. 91:255-264

Ellermeier, C. y Slauch, J. (2006). The genus Salmonella in: Prokaryotes: 6; 123-158

European Food Safety Authority. (2011). Analysis of the baseline survey on the prevalence of Campylobacter in broiler batches and of Campylobacter and Salmonella on broiler carcasses, in the EU, 2008. EFSA Journal 9 (2). Recuperado de: www.efsa.europa.eu/efsajournal

García Jerez, A., \& Quintana Fuentes, L. (2012). Responsabilidad social ambiental de las universidades colombianas. Revista de Investigación Agraria y Ambiental, 3(2), 123-129.

doi:https://doi.org/10.22490/21456453.971

González, L., Martínez, N., Rossi, L., Tornese, M., Troncoso, A. (2010) Enfermedades transmitidas por los alimentos: Análisis del riesgo microbiológico. Rev Chil Infectol. 27(6):513-24.

doi:10.4067/S0716- 10182010000700004.

González, J., Pereira, N., Soto, Z., Hernández, E., Villarreal, J. (2014). Aislamiento microbiológico de Salmonella spp. y herramientas moleculares para su detección. Revista Salud Uninorte, 30 (1) 73 $-94$.

Guerra, A., Trejo, S., Caranguay, M., Paz, M., Ibarra, M., \& Trujillo, E. (2014). Prevalencia de Salmonella ssp. (no tifoideas) en el Departamento de Nariño, Colombia 2011. Univ. Méd., 55(4), 365-373.

Heymann, D. (2005). En control de las enfermedades trasmisibles. 18tava edición. EEUU.

Higgins, J., Higgins, S., Guenther, K., Huff, W., Donoghue, A. \& Donoghue, D. (2005). Use of a specific bacteriophage treatment to reduce Salmonella in poultry products. Poultry Science. 84:11411145.

Humphrey, T. (2004). Salmonella, stress responses and food safety. Nature Reviews. 2: 504-509.

Icontec. (2007). Microbiología de alimentos y alimentos para animales. Método horizontal para la detección de salmonella sp. Recuperado de: https://tienda.icontec.org

Innis, M., Gelfand, D., Snisnky, J., White, T. (2012). PCR Protocols: A Guide to Methods and Applications. California, Estados Unidos.: Academic press.

Instituto Nacional de Salud, INS. (2010). Protocolo de vigilancia y control de Fiebre tifoidea y paratifoidea. Bogotá. Recuperado de:

https://www.minsalud.gov.co/Documentos\%20y\%20Publicaciones/FIEBRE\%20TIFOIDEA\%20Y \%20PARATIFOIDEA.pdf

Jay, J., Loessner, M., Golden, A. (2005). Food Modern Microbiology. Seventh Edition. Springer Science. USA.

Jiménez, R., Arenas, C., Delgado, B., Rivera, B. y Torre, J. (2010). Fiebre tifoidea y otras infecciones por Salmonella. Medicine. 10(52):3497-501

Kimura, A., Reddy, V., Ruthanne, M., Cieslak, P., Mohle-Boetani, J., Kassenborg, H., Segler, S., Hardnett, F., Barrett, T., Swerdlow, D. (2004). Chicken consumption is a newly identified risk 
factor for sporadic Salmonella enterica serotype Enteritidis infections in the United States: a casecontrol study in FoodNet sites. CID; 38: S244-S251

Fearnley, E., Raupach, J., Lagala, F., Cameron, S. (2011). Salmonella in chicken meat, eggs and humans; Adelaide, South Australia, 2008. International Journal of Food Microbiology 146 (3) Recuperado de: www.ncbi.nlm.nih.gov/pubmed/21429610

Food and Agriculture Organization of the United Nations (2004) First Pan-European Conference on Food Quality and Safety: foodborne diseases are on the rise. In Europe-FAO/WHO call for better consumer protection. Recuperado de:

http://www.fao.org/WAICENT/ois/PRESS_NE/english/2002/2920-en.html

Fearnley E, Raupach J, Lagala F, Cameron S. (2011). Salmonella in chicken meat, eggs and humans; Adelaide, South Australia, 2008. Int J Food Microbiol 146: 219-227.

Fernández, M., Aguado, JM., Arribas, A., Lumbreras, A., de Gorgolas, M. (2004). The spectrum of cardiovascular infections due to Salmonella enterica: A review of clinical features and factors determining outcome. Medicine; 83: 123-138.

Master, W. (2016). Producción público. Fenavi.org. Recuperado de: http://www.fenavi.org/index.php?option=com content\&view=article\&id=2472\&/temid=1330

Molina, N., Millán, B. \& Araque M. (2010). Indicadores de calidad sanitaria y fenotipificación de Salmonella enterica aislada de pollo crudo comercializado en el área urbana de Mérida, Venezuela. Infectio 14 (3). Recuperado de: http://www.scielo.unal.edu.co/

Moreno Foglia, O., Trujillo Salinas, C., Maia Cavalcante, C., \& Torres Romero, J. (2015). Diagnóstico y monitoreo de leptospirosis en Latinoamérica. Revista de Investigación Agraria y Ambiental, 6(2), 85 - 96. doi:https://doi.org/10.22490/21456453.1407

Mccann, M., Mcgovern, A., Mcdowell, D., Blair, I. \& Sheridan, J. (2006). Surface decontamination of beef inoculated with Salmonella Typhimurium DT104 or Escherichia coli 0157:H7 using dry air in a novel heat treatment apparatus. Journal of Applied Microbiology. (101):1177-1187

Ministerio de salud y protección social. (2013). Salud Pública, Calidad e Inocuidad de Alimentos.

Recuperado de: https://www.minsalud.gov.co/salud/Documents/general-tempid/ENFERMEDAD\%20TRANSMITIDA\%20POR\%20ALIMENTOS\%20Y\%20SU\%20VIGILANCIA. pdf

Ministerio de protección social y Unidad de Evaluación de Riesgos para la Inocuidad de los Alimentos UERIA. (2011). Perfil de riesgo Salmonella spp. (no tifoideas) en pollo entero y en piezas. Bogotá. Colombia.

Parra, M., Durango, J., Máttar S. (2002). Microbiología, patogénesis, epidemiología, clínica y diagnóstico de las infecciones producidas por Salmonella. MVZ-Córdoba; 7:(2), 187-200

Pascual, M. (2005). Enfermedades de origen alimentario. Madrid: Díaz de Santos.

Pérez, M. (2016). En 2015 el valor de la producción avícola alcanzó 131 mil 404 mdp. La jornada.

Organización mundial de la salud, O. (2016). OMS | Fiebre tifoidea: Uganda. Who.int. Recuperado de: http://www.who.int/csr/don/17-march-2015-uganda/es/ 
Quesada, A., Reginatto, G. A., Ruiz Español, A., Colantonio, L. D., \& Burrone, M. S. (2016). Resistencia antimicrobiana de Salmonella spp aislada de alimentos de origen animal para consumo humano. Revista Peruana de Medicina Experimental y Salud Pública, 33, 32-44.

Realpe, M., Bibiana, A., Donado, P., Rey, L., Díaz, P., \& Arévalo, S. (2016). Epidemiología de Salmonella spp., Listeria monocytogenes y Campylobacter spp., en la cadena productiva avícola. IATREIA, 29(4), 397-406.

Rodríguez, D. (2013). Real-time PCR in Food Science: Current Technology and Applications. Norfolk: Caister Academic Press. -15-7.

Salas-Zapata, W., \& Ríos-Osorio, L. (2013). Ciencia de la sostenibilidad, sus características metodológicas y alcances en procesos de toma de decisiones. Revista de Investigación Agraria y Ambiental, 4(1), 101-111. doi:https://doi.org/10.22490/21456453.987

Silva, J., Recavarren, M., \& Williams, K. (2015). Detección de bacterias patógenas productoras de Enfermedades Transmitidas por Alimentos en carne aviar. (Tesis de pregrado). Recuperado de http://www.ridaa.unicen.edu.ar

Sistema de vigilancia en salud pública, (2016). Semana 42. Bogotá. Recuperado a partir de http://www.ins.gov.co/boletinepidemiologico/Boletn\%20Epidemiolgico/2016\%20Boletin\%20epidemiologico\%20semana\%2042. pdf

Uribe, C. \& Suarez, M. (2006). Salmonelosis no tifoidea y su transmisión a través de alimentos de origen aviar. Colombia Médica, 37(2), 151-158.

Wilfred, S., Thiyageeswaran, M. \& Sharadha R. (2010). Isolation and identification of Salmonella spp. from retail chicken meat by polymerase chain reaction. International Journal of Microbiological Research 1 (3).106-109

Wain, J., Hendriksen, R., Mikoleit, M., Keddy, K., Ochiai, R. (2015). Typhoid fever. Lancet. Mar 21;385(9973):1136-45.

Yánez, E., Máttar, S., Durango A. (2008). Determinación de Salmonella spp. por PCR en tiempo real y método convencional en canales de bovinos y en alimentos de la vía pública de Montería, Córdoba. Infect, 12 (4), $246-253$.

Yen, T., Trun, N., Phuong, P., Da Xuan, P., Hao, L., \& Walid, A. (2012). Prevalence of Salmonella on Chicken Carcasses from Retail Markets in Vietnam. Journal Of Food Protection, 4(10), 1851 1854. 